\title{
Reflections on Using Music Education to Improve the Comprehensive Quality of Higher Vocational Students
}

\author{
Na Zhou \\ Jingzhou Institute of Technology, Jingzhou Hubei, 434020, China
}

Keywords: Music education, Higher vocational education, Comprehensive quality.

\begin{abstract}
Music education is an important part of higher vocational education. It has a very important value in promoting the personality development and perfect personality of higher vocational students. It is especially important for the cultivation of students' overall quality. For a long time, higher vocational schools have paid more attention to technical ability education and have often overlooked the improvement of comprehensive quality. However, the current society has higher requirements for the overall quality of higher vocational students. This requires that the students in vocational colleges should not only possess the technical skills of the major they have studied, but also should create a perfect personality. This requires music education to improve the overall quality of vocational college students. This paper expounds the important role of music education in improving the overall quality of vocational college students, analyzes the common problems existing in higher vocational college music education, and puts forward some countermeasures for applying music education to improve the overall quality of higher vocational college students.
\end{abstract}

\section{Introduction}

With the continuous development of higher vocational education in our country, higher vocational college graduates have become one of the most important components that cannot be ignored in the current society. Strengthening the overall quality of students in higher vocational colleges has become a necessity for social development in the new era. For higher vocational colleges, the construction of campus culture has become an important part of the comprehensive education system for higher vocational students. As an integral part of humanistic quality education, the role of music education in campus culture has become more important. An excellent musical work can not only inspire people with a vivid image, but also can use the profound humanistic spirit to educate people, so that students can use a wealth of associations to enhance moral sentiment and spiritual cultivation. Therefore, higher vocational music educators must use music education to promote the overall quality of higher vocational students.

\section{The Important Role of Music Education in Improving the Comprehensive Quality of Higher Vocational Students}

Firstly, higher vocational music education will have an important influence on the students' world outlook. The study of high vocational students in school is mainly the transition from students to the social man, which is also an important period for the formation of the world view. The group of vocational students has a natural preference for music, which is an important internal cause for the enthusiasm of music learning. Human beings tend to actively accept good things. Music teachers can fully use the world view of music works and use typical art images to guide students to distinguish between truth, goodness and beauty and guide students to pursue truth, goodness, and beauty, and integrate good moral sentiments into the music education system. This will inevitably affect the life of vocational students who are going to enter the workplace, so that they can benefit all their lives. Music and nature are harmonious and unified. Music has a very strong ability to express nature, and music originates from nature. For example, China's ancient song White Snow in Spring has a lively and cheerful rhythm, which can show the beautiful scene of vitality in the early spring. Teachers in 
higher vocational schools should use music education to instruct higher vocational students to feel the harmonious beauty of music. Only in this way can higher vocational students establish correct values.

Secondly, music education in higher vocational colleges has an important influence on the formation of students' outlook on life. The concept of life mainly refers to a person's view of life, which is also the view on the purpose, value, and significance of survival. The concept of life has always influenced the modern people's moral behavior and ideological quality, and thus determines the path people will take in the future. Therefore, the scientific outlook on life is of great significance to the formation of the moral quality of the vocational college students and their choices of future life. The lack of integrity, counterfeiting, feudal superstitions, gambling, and harmful Internet information in the society today have a very bad effect on the students of vocational colleges. As a result, a small number of vocational college students are depressed and even hostile to society. Therefore, higher vocational schools should make good use of music education, continue to strengthen the ideological and political education of the group of higher vocational students, and promote this group to form a correct outlook on life. A large number of classical Chinese songs, such as High Mountain and Running Water, Three Stanzas of Plum Blossoms, etc., cover the characteristics of the great and powerful mountains, the beautiful and deep water and the blooming and tough plum blossoms. The harmonious and unified artistic conception between these people and nature can actually inspire the high vocational students to love their motherland. Therefore, we must make full use of the tremendous spiritual power that is included in the musical works and strengthen the cultivation of good moral sentiments for the students in higher vocational colleges.

Thirdly, higher vocational music education has an important influence on the formation of students' values. Values mainly refer to the individual's overall view of the value of an objective thing, as well as an overall assessment of the results of their own actions. Values are the criteria that guide people's actions. At present, there are still some wrong thoughts in the international and domestic, and in the adult world, there are distorted values, so that the values of some high vocational students have also changed. Part of the value orientation of higher vocational students prematurely appeared the tendency of utilitarian and physical, so hedonism and money worship, bad thoughts appear constantly in the higher vocational students, the physical and mental health of students group suffered great damage. Therefore, it is also necessary to use the important educational function of music education so that students in higher vocational colleges can truly establish the correct values. At the same time, we should play the role of the red classics song in music teaching. For example, classic red songs such as Red Star Song and Union is Strength are full of patriotic passions. By teaching these songs, it is possible to help the vocational students form the correct values.

\section{Problems in Music Education in Higher Vocational Colleges}

Firstly, higher vocational music education has never been concerned. Although music education is an important content of quality education, it has not been taken seriously in some higher vocational schools. A large number of higher vocational schools do not pay attention to the music quality education for students, and a large number of higher vocational schools feel that music lessons are completely the waste of students' time and even the waste of the resources of higher vocational colleges. There are many reasons for this situation, and the fundamental reason is that higher vocational schools themselves are mainly vocational and technical education. Their education of the vocational college students only pays attention to the cultivation of the students' professional and technical skills, but they neglect to improve the overall quality of the students in the higher vocational colleges. Naturally, they neglect music education. At the same time, a large number of higher vocational schools do not pay enough attention to the students' musical literacy. In the concept of higher vocational colleges, they naturally do not pay attention to the improvement of students' musical literacy. Therefore, there are still great deficiencies in music education of higher vocational schools

Secondly, there are deficiencies in the establishment of music courses in vocational colleges. Music education is not only a problem in concept, but also has a lot of problems in the setting of 
music class, so that the music class of high vocational students has a corresponding problem. It is mainly reflected in the following two aspects: On the one hand, there are deficiencies in the setting of higher vocational music theory courses. In the setting of higher vocational music courses, some higher vocational colleges have arranged theoretical courses for two semesters of school hours. This will lead students to become less interested in learning and their own training opportunities have also declined. In the arrangement of the course of theory, a large number of higher vocational schools have led to a single theory course because of teachers and other reasons. Some higher vocational colleges arrange a theoretical course in one semester only, so that students can not master the knowledge of music theory. The separation of theory and practice caused the disconnection between teaching and learning. On the other hand, the music skill class is not well arranged. Usually, the arrangement of music skill courses in higher vocational colleges is the training of vocal music, instrumental music and chorus. The school curriculum is relatively simple, and there is no systematic training. Teachers merely provide theoretical guidance to students, and they will not help students to understand the related problems in learning. The same is true for instrumental training. Teachers only explain the knowledge related to instrumental music in the classroom. They do not have enough time to explain how to perform, so as to cause students to have problems in their music learning, which is not conducive to their improvement of overall quality.

\section{Some countermeasures of applying music education to improve comprehensive quality of vocational students}

Firstly, realizing the mutual unification of education and teaching objectives. In the process of higher vocational education, the purpose of teaching and education should be unified. The purpose of teaching is to make students learn more knowledge, while education aims to further improve the comprehensive quality of vocational students. Therefore, in the process of music education in higher vocational colleges, the two should be unified in the curriculum setting. In the setting, students should be the center. In the course setting, we should not only pay attention to the theory of education, but also give higher vocational students more practical training experience. At the time of arranging theoretical courses, some practical courses should be arranged to realize the close connection between teaching and learning.

Secondly, designing diversified vocational music courses. In view of the continuous development of the society and the integration of various new ideas, the requirements for the personal qualities of high vocational students have also become higher. In the process of education of high vocational students, music education has a tendency of simplification in the curriculum setting, thus resulting in the limitation of education. In fact, music culture will continue to spread with the development of society, which will have a very important influence on learners' outlook on life and values. Therefore, in the process of higher vocational music education, curriculum design should be diversified, so as to comprehensively demonstrate the characteristics of diversification, and actively learn advanced music cultures of other countries based on our native music culture. For example, it is possible to set up Chinese traditional music-related courses in music course arrangement, and then set up foreign music and cultural courses, so as to fully break the limitation of concept of music education and make the learning of higher vocational students more diversified to promote its continuous improvement in a diverse music environment.

Thirdly, the content of patriotic education should be integrated into music curriculum. In the process of higher vocational education in our country, the important significance of quality education has no doubt. The integration of patriotism in higher vocational music teaching is extremely important for improving the overall quality of higher vocational students. Education of patriotism can not only stimulate the patriotic sentiments of students, but also improve the ideological and political qualities of higher vocational students. The integration of patriotic education into music teaching can enable students to feel the national spirit of the Chinese nation's perseverance in music, and lead the students to form optimistic and progressive ideology. Therefore, how should we integrate the patriotic education content into music education? This requires music teachers to teach patriotic 
songs in their teaching. They can also use the piano accompaniment, concerto, and other forms to enhance students' patriotism and enhance the overall quality of higher vocational students.

Fourthly, guiding vocational students to appreciate high quality musical works. In the process of music education in higher vocational colleges, it is necessary to pay attention to the teaching methods and guide students in depth appreciation of outstanding Chinese and foreign musical works. High-quality music works allow students to feel the charm and expand the students' knowledge, especially for the appreciation of famous musical works. For example, the appreciation of Beethoven's series of symphonies and Tchaikovsky's "Swan Lake" can inspire the students' deep understanding of the musical works, it also allows students to be more enthusiastic about music. Therefore, music teachers should introduce multimedia methods and use video, audio and other means to allow students to enjoy music, and then let students feel the passion in the music works to promote their comprehensive cultivation.

Fifthly, making full use of the second classroom. In the process of music education in higher vocational schools, it is not enough to set several music lessons. It is necessary to organize all kinds of activities in order to enrich the lives of students in higher vocational colleges, and use the second classroom to educate the students of higher vocational colleges. In this way, this will not only help students in higher vocational colleges to enrich their lives, but also allow them to continuously improve their musical abilities in a musical atmosphere. For example, vocational colleges can introduce famous musical compositions and musicians to teachers and students through holding music appreciation sessions. Higher vocational colleges may also invite some well-known music experts to set up special lectures so that the students of higher vocational colleges can continuously improve their interest in learning under the guidance of famous artists and further improve their overall quality.

\section{Conclusion}

In general, higher vocational music education has an important role that can not be ignored in improving the overall quality of students. It will not only improve the comprehensive aesthetic ability of students in higher vocational colleges, but also improve their self-cultivation. From the perspective of the art, it promotes the improvement of the personality and development of the personality of the students in higher vocational colleges, so that the students in higher vocational colleges can improve their own cultural accomplishments and aesthetic abilities based on their learning skills, and promote the development of the overall quality of the students in the vocational colleges.

\section{Reference}

[1] Chen Yingjia. The Role of Music Education in the Development of Higher Vocational Students' Comprehensive Quality after 1990s__ Take Shaoxing Vocational and Technical College as an example, Journal of Hubei Correspondence University, 2014(18).

[2] Liu Ling. The Application of Quality Education Idea in Higher Vocational Music Education, Theater House, 2017(6).

[3] Zhang Yehua, Liu Jinxin. Research on National Music in Improving Higher Vocational Students' Comprehensive Quality, Chinese and Foreign Entrepreneurs, 2017(14).

[4] Feng Yuhan. The Application of Quality Education Idea in Higher Vocational Music Education, Journal of Liaoning teachers' College (Social Sciences Edition), 2018(1). 